\title{
Urgences
}

\section{Robert Lebel, Marcel Duchamp , Paris, Belfond, coll. " Les dossiers Belfond ", 1985, 266 p.}

\section{André Gervais}

Numéro 13, mars 1986

\section{Éclats d'atelier}

URI : https://id.erudit.org/iderudit/025252ar

DOI : https://doi.org/10.7202/025252ar

Aller au sommaire du numéro

\section{Éditeur(s)}

Urgences

\section{ISSN}

0226-9554 (imprimé)

1927-3924 (numérique)

Découvrir la revue

Citer ce compte rendu

Gervais, A. (1986). Compte rendu de [Robert Lebel, Marcel Duchamp , Paris, Belfond, coll. " Les dossiers Belfond ", 1985, 266 p.] Urgences, (13), 121-121. https://doi.org/10.7202/025252ar d'utilisation que vous pouvez consulter en ligne.

https://apropos.erudit.org/fr/usagers/politique-dutilisation/ 
leur souvenir (Gallimard, 1984), Françoise Sagan évoque la figure de "cette femme qui était pour moi le meilleur écrivain, le plus sensible en tout cas de l'Amérique d'alors: Carson McCullers" (p. 62-63). Alors, c'était au milieu des années 1950; née en 1917. Carson McCullers allait mourir en 1967. Et pour mieux comprendre la romancière du Coeur, lire la biographie délicate et attentive qui lui a consacrée l'un de ses traducteurs, Jacques Tournier. Retour à Nayack, parue au Seuil en 1979.

\section{Renald Bérubé}

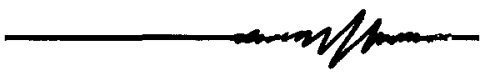

\section{Robert Lebel: Marcel Du- champ, coll. "Les dossiers Bel- fond", Paris, Belfond, 1985 , $266 \mathrm{p}$.}

Robert Lebel a commencé vers 1949 et publié en 1959 le premier livre sur Marcel Duchamp, artiste et anartiste français et américain (1887-1968). Ainsi intitulé, Sur Marcel Duchamp est un album grand format illustré de plus de 170 planches et documents photographiques divers, plein d'amorces analytiques, contenant une première biographie (puisée à la source même et intégrée, au fur et à mesure, aux analyses), un premier catalogue raisonné et un premier ensemble bibliographique. Le tout s'arrête, pour des raisons évidentes, à l'automne 1958. Duchamp, alors, a 71 ans.

Cet album, publié simultanément en français (Paris) et en traduction anglaise (Londres et New York), constitue, avec une première édition (incomplète, il va sans dire) des Écrits et Parlés de Duchamp notes, aphorismes, entrevues, etc. -, édition préparée par Michel Sanouillet, intitulée Marchand du sel (contrepet syllabique de Mar/cel/Du/champ, proposé en 1922 par le poète Robert Desnos dans un petit recueil qui met en scène l'alter ego féminin de l'artiste: "Rrose Sélavy connaît bien le marchand du sel") et publiée aussi en 1959, le diapason dont la résonance transatlantique s'entend clairement, durant les années 60, dans I' "art". L'art moderne, en effet, peut-on dire après Octavio Paz, aura vécu, a vécu entre l'oeuvre très variée bien que mince, froide et ironique, très articulée picturalement et langagièrement de Duchamp (1902-1968) et l'oeuvre proliférante, envahissante, engloutissante, pieine de reprises et de variantes de Picasso (1889-1973). Comme la littérature française, au XIXe siècle, aura vécu entre Rimbaud et Hugo.

Eh bien, l'essentiel de cet album est devenu, dans un texte revu, corrigé et fort augmenté - de dix chapitres, écrits entre 1966 et 1982, eux-mêmes corrigés et augmentés, et d'un avant-propos -, le livre en question.

De loin, le plus complet et le plus critique de tous les livres portant sur l'ensemble de l'oeuvre duchampienne qu'il n'est pas sans situer, via le paradigme de la collection où il paraît - collection qui propose des livres sur Beckett, Breton, Freud, Joyce et Proust, par exemple -, parmi les plus importantes oeuvres du XXe siècle.

À lire, donc, avant d'entrer dans d'autres livres plus difficiles, plus techniques, plus terribles en quelque sorte: ceux, disons, de Jean-François Lyotard (1977). Craig Adcock (1983), André Gervais (1984) et Thierry de Duve (1984). Les références sont dans la "bibliographie essentielle" de ce livre.

André Gervais

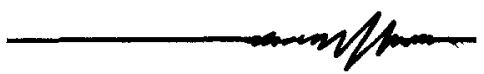

